\title{
Towards new methodologies for the synthesis of biologically interesting 6-substituted pyrimidines and 4(3H)-pyrimidinones
}

\author{
Elena Petricci, Claudia Mugnaini, Marco Radi, Andrea Togninelli, Cesare Bernardini, \\ Fabrizio Manetti, Maria Cristina Parlato, Michela Lucia Renzulli, Maddalena Alongi, \\ Chiara Falciani, Federico Corelli, and Maurizio Botta*
}

Dipartimento Farmaco ChimicoTecnologico, Università degli Studi di Siena

Via Aldo Moro- 53100 Siena, Italy

E-mail: botta@unisi.it

\begin{abstract}
The present paper describes the application of modern combinatorial and microwave assisted techniques for the lead discovery and optimization of novel non-nucleoside HIV-1-RT inhibitors. Starting from the parallel solid phase synthesis of highly substituted pyrimidinone derivatives, compound 12c was identified as interesting lead compound for further structure optimizations. The generation and screening of a small virtual combinatorial library led to the optimization of the lead structure 12c to give highly active derivatives (against HIV1-RT wild-type and mutant strains) in the nanomolar range. Moreover, a straightforward three-step parallel solution phase approach was developed for the generation of a small library of novel 4-dialkylamino-2methylsulfonyl-6-vinylpyrimidines which were obtained in high yield after a simple ethyl acetate extraction with no need of further purification. Surprisingly, some of these derivatives showed a new competitive inhibition of HIV1-RT never reported in the literature for this class of compounds. Molecular modeling calculations were also performed to investigate the binding mode of all synthesized compounds onto the non-nucleoside reverse transcriptase inhibitor binding site and to rationalize the relationships between their chemical structure and activity.
\end{abstract}

Keywords: Pyrimidinones, $S$-DABOs, anti-HIV, solid phase organic synthesis, solution phase parallel synthesis, combinatorial chemistry, microwave-assisted organic synthesis, virtual libraries

\section{Contents}

Introduction

1. Towards new anti-HIV derivatives

1.1 Solid Phase approach to new NNRTIs 
1.2. Solution phase parallel synthesis and biological evaluation of new $S$-DABO analogues

1.3. Parallel solution phase synthesis of 2-methylsulfonyl-4-dialkylamino-6-vinyl pyrimidines Conclusions

\section{Introduction}

Following a flurry of genomics and proteomics research in the late 1990s, an incredible number of new potential target proteins have been available to pharmaceutical companies.

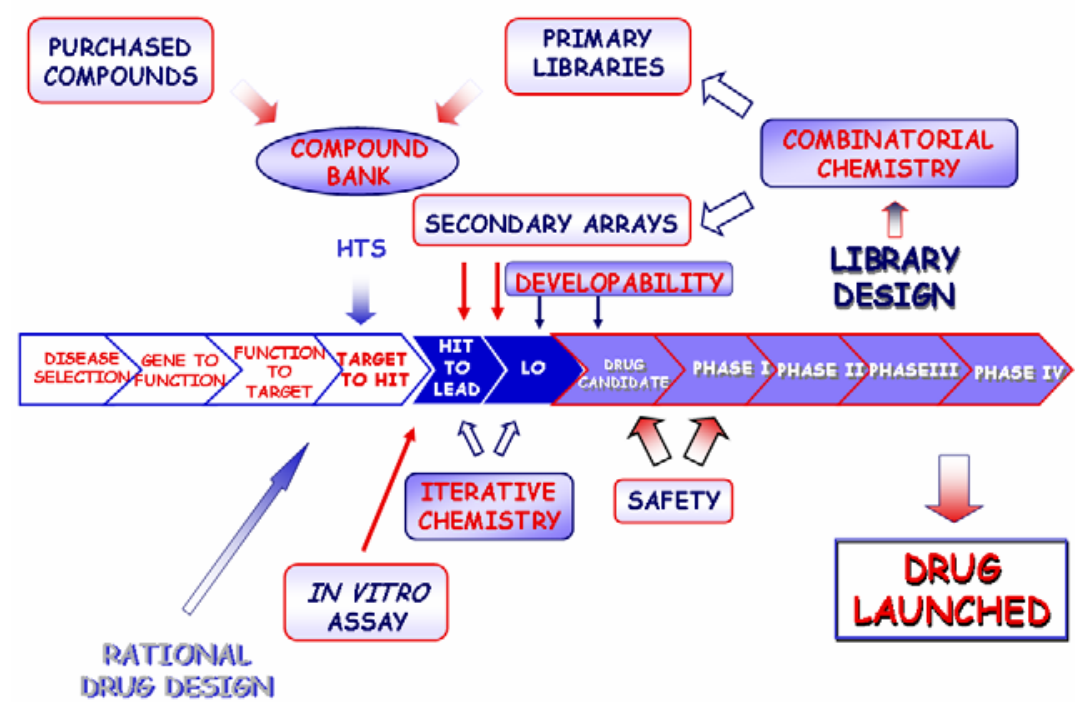

Figure 1. The bottleneck in the Drug Discovery Process.

This fact, combined with the great technological advances associated with high throughput screening (HTS) and high throughput parallel chemistry resulted in a wide number of potential "hits" available for each new biological/protein target. While pharmaceutical companies can identify a reasonably short period of time several "hits" for their target, the subsequent phase of "lead optimization" (LO) still represents a bottleneck for the entire drug discovery process (Figure1).

The first important step in drug discovery process is the identification of new compounds (hits) endowed with interesting biological activitiy. ${ }^{1}$ Different approaches are actually available for discovery of new hits.

Virtual screening ${ }^{2}$ is a computational method used to reduce the burden of high-throughput screening by selecting subsets with higher hit rates for experimental testing. It works by docking each compound from a large electronically available collection individually into a binding pocket of a drug target and could provide new starting points for drug discovery. 
An alternative method for identifying new hits is the screening of huge compound collections (>300,000 compounds). These collections usually consist of compounds from previous programs and from random or targeted chemical combinatorial libraries (1,000100,000 compounds). Hits identified in any of the above described approaches may be optimized to lead compounds by preparing focused libraries (10-1,000 compounds) which are completely SAR driven. Other start points for focused libraries might be $i$ ) hits identified from screening which have no combinatorial chemistry history. To quantify for a combinatorial chemistry type optimization these hits should be accessible in approximately five synthetic steps or less using well developed chemistry; ii) compounds identified in the public domain.

A further level of optimization is usually required to reach a compound for (pre)clinical development. The identified lead compound is optimized further in a program that is focused on phase III items (in vivo activity, bioavailability, etc.). In this phase the power of combinatorial chemistry gradually diminishes with the requirements of smaller numbers but larger quantities and higher purities. The final rounds of fine-tuning the molecule are usually done with classical synthetic method but the impact of combinatorial chemistry in drug discovery is remarkable. ${ }^{3-6}$ As a part of a project devoted to the development of new antiviral compounds we have focused our attention on the application of modern combinatorial and microwave assisted techniques for the lead discovery and optimization of novel non-nucleoside HIV-1-RT inhibitors.

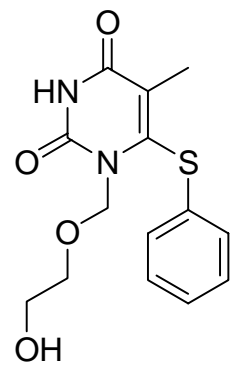

HEPT

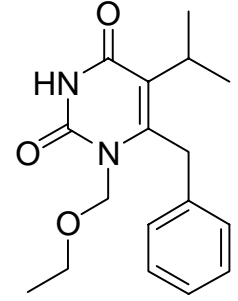

Emivirine (EMV)

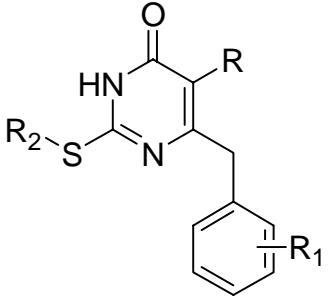

S-DABOs

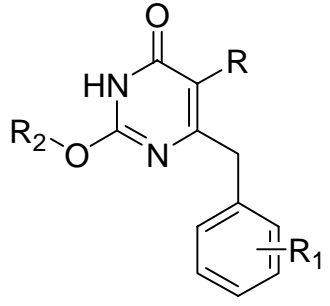

DABOs

Figure 2. 6-Substituted pyrimidinones active against HIV-1.

\section{Towards new anti-HIV derivatives}

In the present era, acquired immunodeficiency syndrome (AIDS) is the most fatal disorder for which no completely successful chemotherapy has been developed so far. ${ }^{7}$ The rapid spread of the AIDS epidemic has stimulated the search for new agents able to arrest the replication of the causative virus, HIV. The best strategy for AIDS treatment involves a combination therapy using inhibitors of reverse transcriptase and protease. However, the emergence of HIV-1 strains resistant to these drugs and their cytotoxicity requires the synthesis of new antiviral drugs, as well as the development of newer strategies and viral targets. In the last few years, 6-substitued 
pyrimidines, as for example 1-[(2 hydroxyethyl)methyl]-6-(phenylthio)thymine (HEPT), ${ }^{9}$ 3,4dihydro-2-alkoxy 6-benzyl-4-oxopyrimidines (DABOs), ${ }^{10}$ and diarylpyrimidine analogues $(\mathrm{DAPY})^{11-13}$ showed a potent and selective activity against reverse transcriptase (RT) of human immunodeficiency virus type-1 (HIV-1) (Figure 2). Moreover, the finding that C-6 substituted pyrimidinone and pyrimidindione derivatives showed selective antitubercolar, ${ }^{14}$ antitumor, ${ }^{15-16}$ antipsycotic ${ }^{17-18}$ as well as antifungal ${ }^{19}$ activities underline the importance of this heterocyclic moiety as pharmacophoric structure. In fact, we have also reported how 2-methoxy- and 2methylthio-6-[(2-alkylamino)ethyl]-4(3H)-pyrimidinones showed an interesting biological activity against positive strand (Rubella virus and Sendai virus) and negative strand (vescicular stomatitis virus) RNA viruses. ${ }^{20}$<smiles>[R]Oc1nc([R2])c([R1])c(=O)[nH]1</smiles><smiles>[R]c1[nH]c(=O)[nH]c(=O)c1[R2]</smiles>
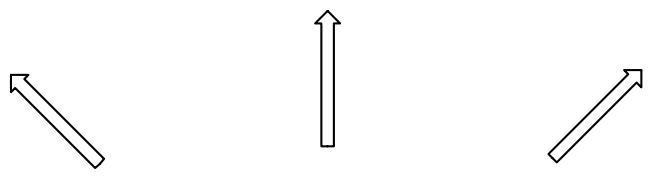<smiles>[R]c1c([R2])n(C(=O)Br)c(OC)nc1=O</smiles><smiles>[R]c1nc(N([R])[R])[nH]c(=O)c1[R]</smiles><smiles>C=C</smiles><smiles>[R]c1nc(OC)[nH]c(=O)c1[R]</smiles><smiles>C=C</smiles><smiles>[R]C(=O)Oc1nc(OC)nc([R2])c1[R]</smiles><smiles>[R]c1[nH]c(=O)nc(N)c1[R2]</smiles><smiles>[R2]c1ncnc(N)c1[R4]</smiles>

Figure 3. Functionalization of scaffold $\mathbf{I}$.

It is therefore evident how the high functionalization of this pyrimidinone pharmacophoric structure by means of combinatorial techniques, ${ }^{21,22}$ represent a valuable tool for the identification and optimization of new active lead compounds. As summarized in Figure 3, the pyrimidinone scaffold $\mathbf{I}$ can in fact be easily functionalized to give a wide range of structurally related compounds and studies in this field are on going in our lab from decades. ${ }^{8,24-28}$ 


\subsection{Solid phase approach to new NNRTIs}

Moreover, one of the most efficient procedures for the synthesis of this scaffold by condensation of $O$-methylisourea or $S$-methylisothiourea with different $\beta$-ketoesters has been reported from our group. ${ }^{27}$

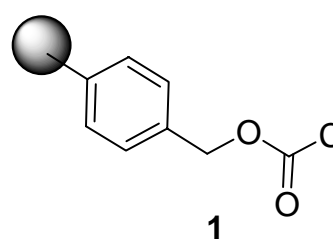

1
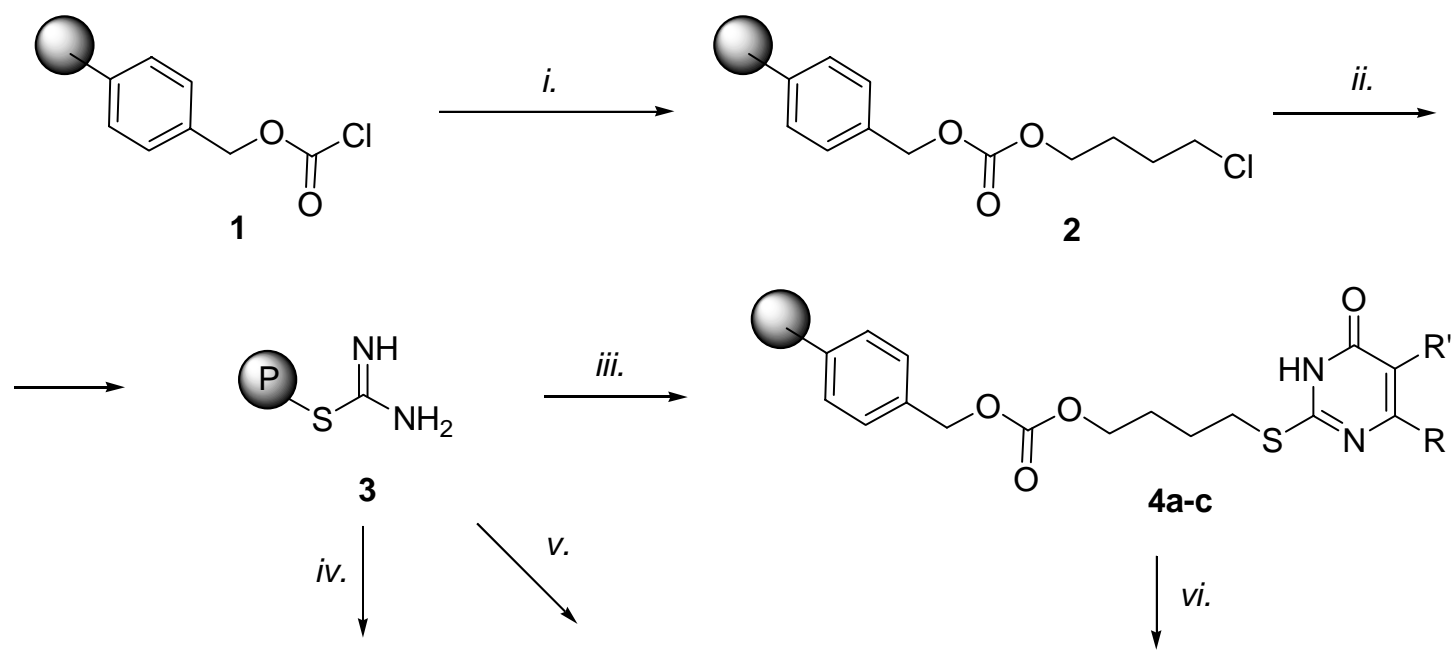

2<smiles>[R]c1nc(SCCCCO)[nH]c(=O)c1[R]</smiles>

7a-c

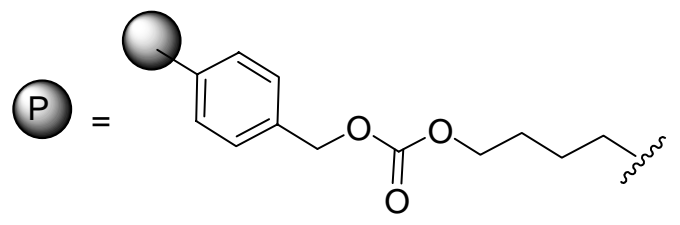

a, $\mathbf{R}=\mathbf{R}^{\prime}=\mathrm{Me} ; \mathrm{b}, \mathrm{R}=\mathrm{Me}, \mathrm{R}^{\prime}=\mathrm{H} ; \mathrm{c}, \mathrm{R}=\mathrm{CH}_{2} \mathrm{Ph}, \mathrm{R}^{\prime}=\mathrm{H}$

Scheme 1. Reagents and conditions: i.4-chlorobutanolo, $\mathrm{CH}_{2} \mathrm{Cl}_{2}, \mathrm{Py}$; ii. thiourea, EtOH/dioxane; iii. $\beta$-ketoester, $\mathrm{Ca}(\mathrm{OH})_{2}, \mathrm{H}_{2} \mathrm{O}, \mathrm{MeOH} ; i$. $\beta$-ketoester, $\mathrm{MeONa} / \mathrm{MeOH} ; \quad$. $\beta$-ketoester, $\mathrm{BuONa} / \mathrm{BuOH}$; vi. TFA $60 \%, \mathrm{CH}_{2} \mathrm{Cl}_{2}$.

In order to exploit the high flexibility of the pharmacophoric structure I, we became involved in the application of solid phase techniques for the development of combinatorial libraries. In a first note, ${ }^{25}$ we reported the development of a flexible linker for the solid phase synthesis of different pyrimidinone derivatives (Scheme 1). The carbonate moiety used to attach the heterocyclic moiety to the solid support (Merrifield resin) can be selectively cleaved to afford compounds 7a-c. In addition, using different alkoxides in place of calcium hydroxide in the cyclization reaction allowed the obtainment of compounds 5a-c and 6a-c directly from 3 . As expected, we also noticed that the tetramethylene spacer was able to create a chemical distance 
between the pyrimidinone nucleus and the polymer backbone and to confer more 'solution like' properties and better solvent compatibility to the resin. Moreover, it was of potential utility for the NMR analysis of the polymer-bound compounds. ${ }^{32-34}$

In order to maximize the number of different product obtainable after cleavage from the solid support, we developed a more acid stable linker coming from the introduction of an ether moiety in place of the acid labile carbonate. ${ }^{42}$ Consequently, it would also be possible to use these solid supported pyrimidinones in the Lewis acid catalyzed synthesis of pyrimidine nucleosides. The potential applications of this solid supported pyrimidinone are depicted in Figure 4. ${ }^{29-31}$

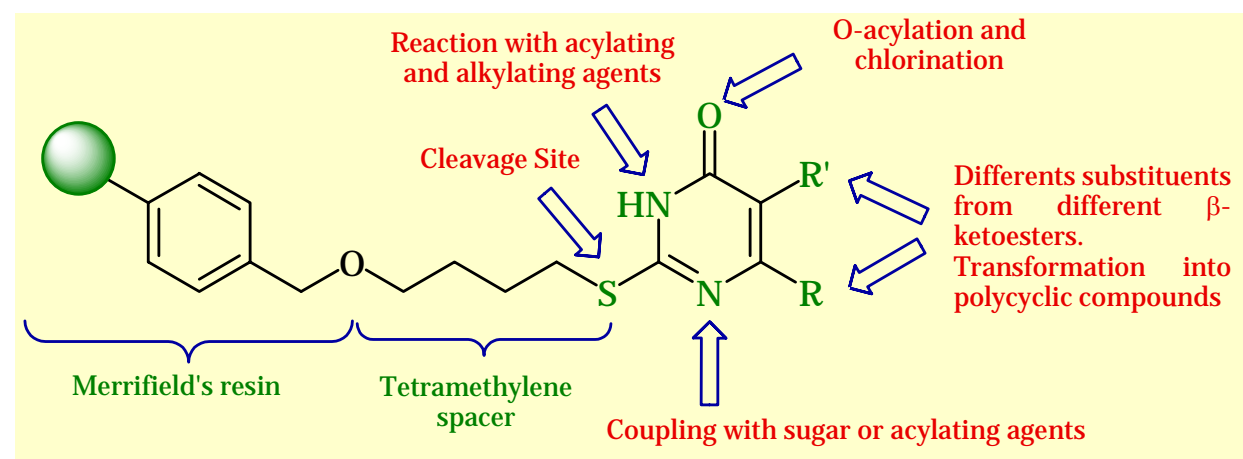

Figure 4. Potential functionalizations of solid supported pyrimidinone moiety.

This new linker turned out to be stable under many different reaction conditions commonly used for ether and thioether bond cleavage: reduction with sodium/ammonia, acid catalyzed hydrolysis, or reaction with heavy metal ion followed by treatment with hydrogen sulfide, ${ }^{35}$ reaction with iodotrimethylsilane, ${ }^{36,37}$ and Pummerer reaction. ${ }^{38,39}$ However, Oxone ${ }^{\circledR}$ (potassium peroxymonosulfate), an efficient and selective oxidizing agent, ${ }^{40}$ was proved to be a suitable reagent for the cleavage of the thioether bond in a traceless way ${ }^{41}$ (Scheme 2).

Swelling the resins 8a-d in a solution of dioxane/water, followed by refluxing in the presence of Oxone ${ }^{\circledR}$ products 10a-d were obtained. In order to drive reaction to completion, the cleavage step was repeated twice under the same experimental conditions to give highly pure substituted uracils 10a-d in 78-98\% yield (Table 1). When methanol was used as solvent in the cleavage reaction, the corresponding 2-methoxy derivatives 5a-d were obtained in 67-95\% yield. ${ }^{41}$ This original and highly efficient cleavage procedure was also used in the case of Wang resin supported pyrimidinones 9a-d affording compounds 10a-d and 5a-d in comparable yields (Table 1). Using instead an acid cleavage procedure (5\% TFA) on compound 9a-d, the corresponding 2-thiouracils 11a-d were obtained as only products. Moreover, using a more concentrated TFA solution (from $10 \%$ to $25 \%$ ) in the reaction with 9a-d gave mixtures of compounds 11a-d and 12a-d characterized by the presence of growing percentages of the former (Scheme 2). ${ }^{45}$ 

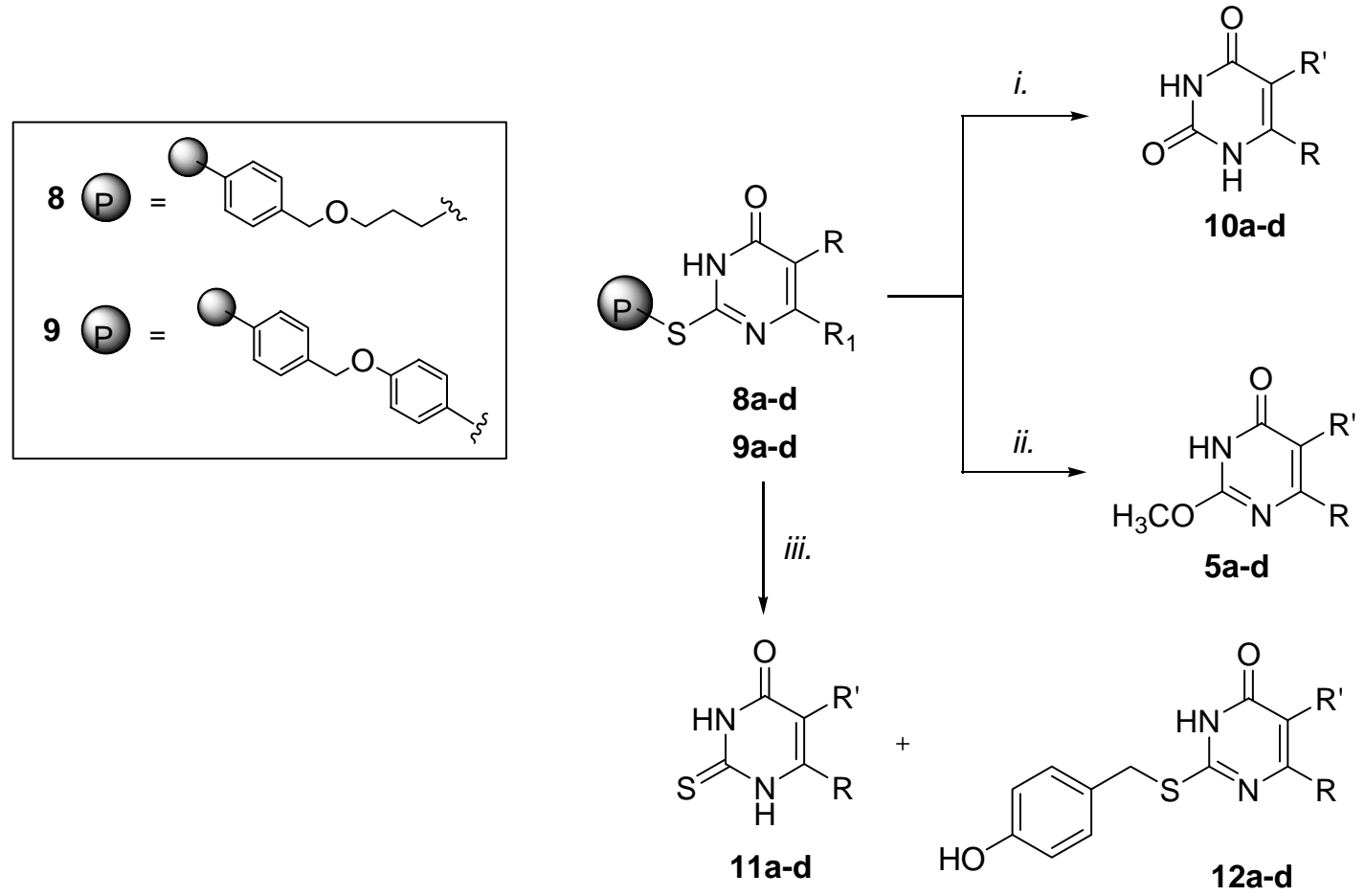

Scheme 2. Reagents and conditions: i. Oxone ${ }^{\circledR}, \mathrm{H}_{2} \mathrm{O} /$ dioxane, reflux, overnight; ii. Oxone ${ }^{\circledR}$, $\mathrm{MeOH}$, reflux, overnight; iii. TFA from 5 to $25 \%, \mathrm{CH}_{2} \mathrm{Cl}_{2}$.

Table 1. Derivatives obtained from 8a-d and 9a-d using Oxone ${ }^{\circledR}$ and TFA cleavage methodologies

\begin{tabular}{|c|c|c|c|c|}
\hline \multirow{2}{*}{ Compd } & \multirow{2}{*}{$\mathrm{R}$} & \multirow{2}{*}{$\mathrm{R}^{\prime}$} & \multicolumn{2}{|c|}{ Yield (\%) } \\
\hline & & & yield- $1^{\text {a }}$ & yield- $2^{b}$ \\
\hline $5 a$ & $\mathrm{Me}$ & $\mathrm{Me}$ & 72 & 70 \\
\hline $5 b$ & $\mathrm{Me}$ & $\mathrm{H}$ & 95 & 96 \\
\hline $5 c$ & $-\mathrm{CH}_{2} \mathrm{Ph}$ & $\mathrm{H}$ & 77 & 73 \\
\hline $5 d$ & $-\mathrm{CH}_{2} \mathrm{COOEt}$ & $\mathrm{H}$ & 67 & 56 \\
\hline $10 a$ & $\mathrm{Me}$ & $\mathrm{Me}$ & 83 & 78 \\
\hline $10 b$ & $\mathrm{Me}$ & $\mathrm{H}$ & 98 & 95 \\
\hline $10 c$ & $-\mathrm{CH}_{2} \mathrm{Ph}$ & $\mathrm{H}$ & 85 & 70 \\
\hline 10d & $-\mathrm{CH}_{2} \mathrm{COOEt}$ & $\mathrm{H}$ & 78 & 65 \\
\hline $11 a$ & $\mathrm{Me}$ & $\mathrm{Me}$ & - & 78 \\
\hline $11 b$ & $\mathrm{Me}$ & $\mathrm{H}$ & - & 70 \\
\hline 11c & $-\mathrm{CH}_{2} \mathrm{Ph}$ & $\mathrm{H}$ & - & 80 \\
\hline 11d & $-\mathrm{CH}_{2} \mathrm{COOEt}$ & $\mathrm{H}$ & - & 72 \\
\hline
\end{tabular}

${ }^{a}$ Cleavage from Merrifield resin ${ }^{\mathbf{b}}$ Cleavage from Wang resin 
In summary, starting from the solid supported compounds 4a-c, 8a-d and 9a-d, it has been possible to generate six types of pyrimidinone derivatives $(5,6,7,10,11,12)$ bearing different substituents on $\mathrm{C} 2, \mathrm{C} 5$ and $\mathrm{C} 6$. Subsequent biological evaluations revealed a moderate activity $\left(\mathrm{K}_{\mathrm{i}}=60 \mu \mathrm{M}\right)$ of compound 12c $\left(\mathrm{R}^{\prime}=\mathrm{H}, \mathrm{R}=\mathrm{CH}_{2} \mathrm{Ph}\right)$ as $\mathrm{HIV}-1 \mathrm{RT}$ inhibitors and therefore this compound was selected as lead for further structure optimization.

\subsection{Solution phase parallel synthesis and biological evaluation of new $S$-DABO analogues}

Based on 12c, a small virtual combinatorial library was therefore designed and generated. In details, the pyrimidinone scaffold was used as a core endowed with 3 different substitution points (position 2, 5 and 6 , namely $\mathrm{R}_{2}, \mathrm{R}_{3}$, and $\mathrm{R}_{1}$ respectively as in figure 5); a peculiar set of chemical moieties was carefully selected for every $\mathrm{R}$ group. In particular the results from our previous work were taken into account together with what reported more recently in literature and the results of the selection are shown in Figure 5.

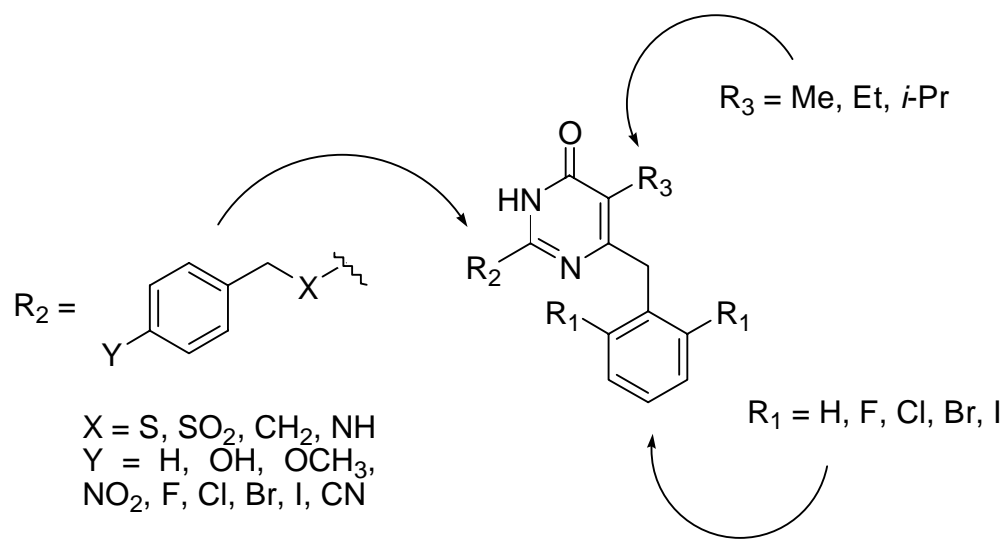

Figure 5. Fragments for virtual library generation.

Then, a combinatorial explosion was performed, and a 552 compounds library was obtained. The library was screened performing an automated flexible docking into the nonnucleoside binding pocket (NNBP) by means of the Autodock 3.0 software package; the compounds were then ranked in order of decreasing energy of binding. 


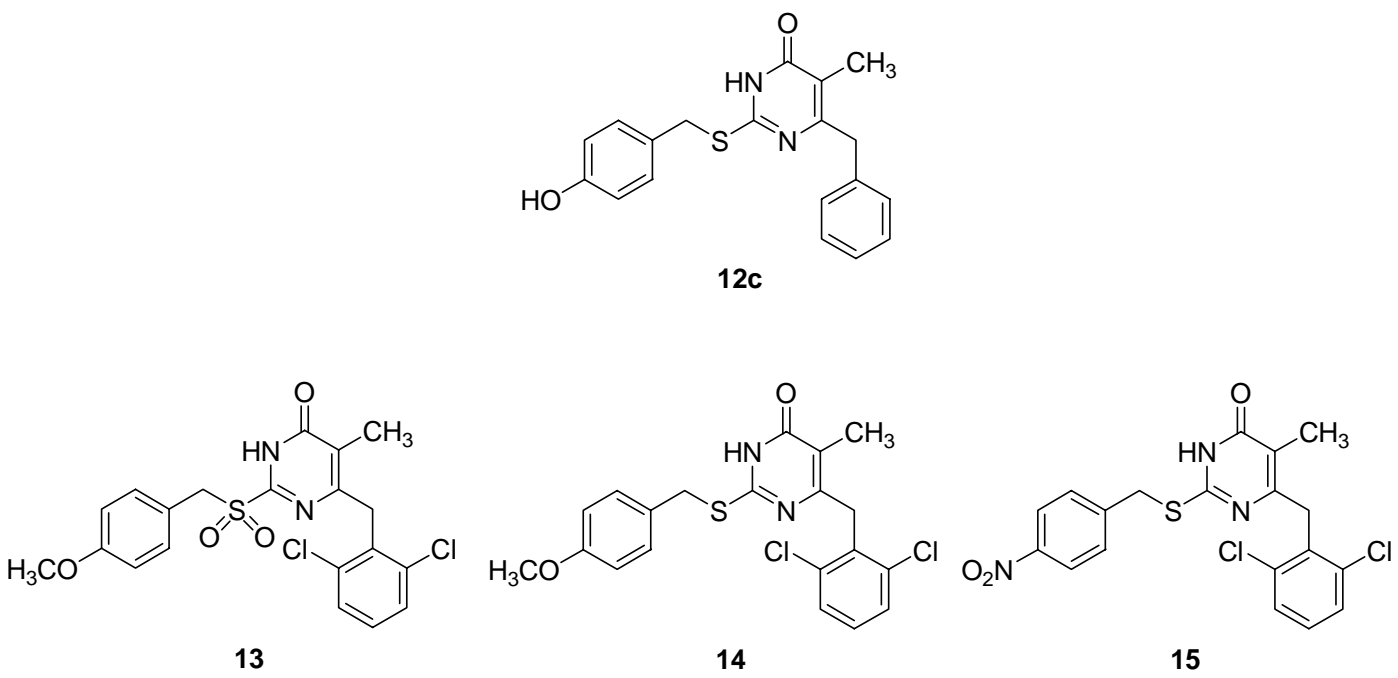

Figure 6. Selected compounds from the virtual library generated starting from lead compound 12c.

Early results showed that all molecules were estimated into a $5.2 \mathrm{Kcal} / \mathrm{mol}$ energy window, and some of them were chosen to be synthesized following what the docking evidenced: chlorine group favored in $\mathrm{R}_{1}$, and ethyl or methyl in $\mathrm{R}_{3}$, while several moieties were analyzed in $\mathrm{R}_{2}$. Finally compounds 13-15 (Figure 6) were firstly synthesized and tested as anti-HIV agents.

Encouraged by biological data obtained from compounds 13-15 (Table 2) we designed a number of $S$-DABO derivatives characterized by the presence of $i$ ) an arylalkylthio substituent at position 2. To expand the SAR of $S$-DABOs, the substitution pattern on the phenyl ring was broadly varied, as well as the length of the alkyl spacer, which was increased from one to three carbon atoms, ii) a 5-methyl group which was kept fixed in all the molecules, as a conformational constraint with the aim of enhancing the affinity for the enzyme, iii) a halogenated benzyl group at the 6 position, which was expected to improve a putative $\pi$-stacking interaction between the electron deficient benzene ring of the ligand and the electron-rich benzene ring of Tyr188 located in the NNBP of the enzyme. ${ }^{46}$ Therefore we have set up a simple and efficient methodology for the parallel solution-phase synthesis of thiouracils 20-22 using Büchi Syncore synthesizer (Scheme 3).

Potassium ethyl 2-methylmalonate (16) was partitioned into three reaction vessels and reacted with three substituted phenylacetyl imidazolides in the presence of a magnesium dichloride/triethylamine system in acetonitrile according to the Clay procedure ${ }^{47}$ to give, after a simple liquid-phase extractive purification, the $\beta$-ketoesters 17-19. Subsequent condensation of 17-19 with thiourea in the presence of sodium ethoxide in refluxing ethanol afforded 6-benzyl2,3-dihydro-5-methyl-2-thioxopyrimidin-4(1H)-ones 20-22. Exploitation of this procedure might allow the rapid synthesis of a large number of $S$-DABO derivatives variously substituted at positions 2, 5, and 6 for further SAR studies in this class of compounds. 5,6-Disubstituted thiouracils 20-22 were selectively $S$-benzylated under microwave irradiation with the appropriate 
substituted benzyl halide in dry DMF in the presence or not of potassium carbonate (Method A) (Scheme 4). ${ }^{44}$<smiles>[R1]c1cccc(Cc2[nH]c(=S)[nH]c(=O)c2C)c1</smiles>

Scheme 3. $i$. a) $\mathrm{MgCl}_{2}, \mathrm{Et}_{3} \mathrm{~N}, \mathrm{CH}_{3} \mathrm{CN}, \mathrm{rt}, 360 \mathrm{rpm}, 2 \mathrm{~h}$; b) substituted phenylacetic acid, $N, N^{\prime}-$ carbonyldiimidazole, rt, $360 \mathrm{rpm}$, overnight then reflux, $360 \mathrm{rpm}, 2 \mathrm{~h}$; c) 13\% HCl, rt, $360 \mathrm{rpm}$, $10 \mathrm{~min}$; ii. thiourea, EtONa, reflux, $360 \mathrm{rpm}$, overnight.<smiles>[R1]c1cccc(Cc2[nH]c(=S)[nH]c(=O)c2C)c1</smiles>

20-22<smiles>[Y]Sc1nc(Cc2ccccc2)c(C)c(=O)[nH]1</smiles>

$14,15,23-36$

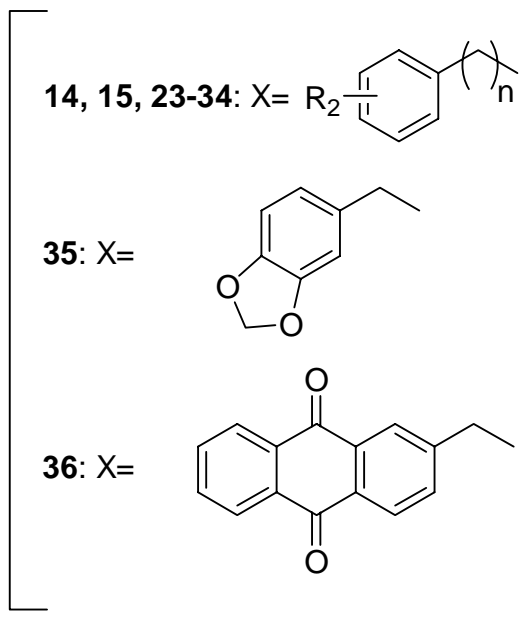<smiles>[R][R]1ccc(CSc2nc(Cc3ccccc3)c(C)c(=O)[nH]2)cc1</smiles>

$14,15,23$<smiles>[R][R]1ccc(CS(=O)(=O)c2nc(Cc3ccccc3)c(C)c(=O)[nH]2)cc1</smiles>

$13,37-38$

Scheme 4. $i$. Substituted benzyl halide, DMF, $130^{\circ} \mathrm{C}, 5 \mathrm{~min}$ (Method A) or substituted benzyl alcohol, trimethylphosphine, DIAD, DMF, MW, 40 $\mathrm{C}, 10 \min ($ Method B); ii. m-CPBA, $\mathrm{CH}_{2} \mathrm{Cl}_{2}$, rt, 360 rpm, overnight. 
Alternatively, 20-22 were $S$-benzylated using the appropriate benzyl alcohol via a microwave-assisted Mitsunobu reaction in the presence of trimethylphosphine and diisopropylazodicarboxylate (DIAD) in dry DMF (Method B). In both cases, the use of microwaves allowed us to obtain, in a few minutes, the desired products in high yield and good purity.

Title compounds 13-15, 23-38, a new family of $S$-DABOs characterized by the presence of an arylalkylthio substitution at C-2, a methyl group at C-5, and a halogenated benzyl group at C6 of the pyrimidinone nucleus, were prepared in a straightforward fashion by alkylation of three different 6-substituted 2-thiouracils (20-22) and subsequent oxidation of the sulfur atom (13, 37, and 38). ${ }^{48-49}$

Table 2. Chemical and Physical Data of Derivatives 13-15, 23-36 and 37-38

\begin{tabular}{cccccc}
\hline Compd & $\mathrm{R}_{1}$ & $\mathrm{R}_{2}$ & $\mathrm{n}$ & Yield $(\%)$ & $\begin{array}{c}\text { Method of } \\
\text { synthesis }\end{array}$ \\
\hline $\mathbf{1 3}$ & $2,6-\mathrm{diCl}$ & $4-\mathrm{OCH}_{3}$ & 1 & 71 & \\
$\mathbf{1 4}$ & $2,6-\mathrm{diCl}$ & $4-\mathrm{OCH}_{3}$ & 1 & 72 & $\mathrm{~A}$ \\
$\mathbf{1 5}$ & $2,6-\mathrm{diCl}$ & $4-\mathrm{NO}_{2}$ & 1 & 55 & $\mathrm{~A}$ \\
$\mathbf{2 3}$ & $2,6-\mathrm{diCl}$ & $4-\mathrm{Br}^{2}$ & 1 & 67 & $\mathrm{~A}$ \\
$\mathbf{2 4}$ & $2,6-\mathrm{diCl}$ & $4-\mathrm{OH}$ & 1 & 64 & $\mathrm{~B}$ \\
$\mathbf{2 5}$ & $2,6-\mathrm{diCl}$ & $4-\mathrm{OCH}_{2} \mathrm{CH}_{3}$ & 1 & 73 & $\mathrm{~B}$ \\
$\mathbf{2 6}$ & $2,6-\mathrm{diCl}$ & $4-\mathrm{OBu}$ & 1 & 79 & $\mathrm{~B}$ \\
$\mathbf{2 7}$ & $2,6-\mathrm{diCl}$ & $4-i \mathrm{Pr}^{2}$ & 1 & 60 & $\mathrm{~A}$ \\
$\mathbf{2 8}$ & $2,6-\mathrm{diCl}$ & $4-\mathrm{CN}^{2}$ & 1 & 78 & $\mathrm{~A}$ \\
$\mathbf{2 9}$ & $2,6-\mathrm{diCl}$ & $4-\mathrm{OCH}_{3}$ & 2 & 53 & $\mathrm{~B}$ \\
$\mathbf{3 0}$ & $2,6-\mathrm{diCl}$ & $4-\mathrm{OCH}_{3}$ & 3 & 67 & $\mathrm{~B}$ \\
$\mathbf{3 1}$ & $2,6-\mathrm{diF}$ & $4-\mathrm{OCH}_{3}$ & 1 & 52 & $\mathrm{~A}$ \\
$\mathbf{3 2}$ & $2,6-\mathrm{diF}$ & $4-\mathrm{NO}_{2}$ & 1 & 40 & $\mathrm{~A}$ \\
$\mathbf{3 3}$ & $4-\mathrm{F}$ & $4-\mathrm{NO}_{2}$ & 1 & 56 & $\mathrm{~A}$ \\
$\mathbf{3 4}$ & $4-\mathrm{F}$ & $4-\mathrm{OCH}_{3}$ & 1 & 63 & $\mathrm{~A}$ \\
$\mathbf{3 5}$ & $2,6-\mathrm{diCl}$ & & 1 & 58 & $\mathrm{~B}$ \\
$\mathbf{3 6}$ & $2,6-\mathrm{diCl}$ & & 1 & 69 & $\mathrm{~B}$ \\
$\mathbf{3 7}$ & $2,6-\mathrm{diCl}$ & $4-\mathrm{NO}_{2}$ & 1 & 55 & \\
$\mathbf{3 8}$ & $2,6-\mathrm{diCl}$ & $4-\mathrm{Br}$ & 1 & 50 & \\
\hline
\end{tabular}

The new compounds were evaluated in enzymatic tests for their ability to inhibit either wild-type (wt) or mutated RTs as well as on MT-4 cells for cytotoxicity and anti-HIV-activity, in comparison with nevirapine (nev) and efavirenz (efa), used as reference drugs. In particular, the following mutants were used: K103N and Y181I for enzymatic tests, K103N, Y188L, and pluriresistant virus (IRLL98) (bearing the K101Q, Y181C, and G190A mutations conferring resistance to nev, delavirdine, and efa, respectively) for tests on cell lines. The results of these 
assays are reported in Table 3. Moreover, Table 3 reports fold-resistance values of selected compounds against a panel of mutant strains, in comparison to those of AZT, nev, and efa. Although previous findings obtained with other $S$-DABO series highlighted the importance for optimal activity of a 2,6 difluorobenzyl substituent at position $6,{ }^{43}$ in our case this type of substitution proved to be less profitable with respect to the corresponding 2,6-dichlorobenzyl group. In fact, although compound 14 was highly active both in enzymatic and cell tests, showing appreciable activity also against IRLL98, compound $\mathbf{3 1}$ retained activity only against the wt RT. Moreover, a striking difference in activity can be observed between that of 15 (displaying a full-range activity at low concentrations so as to emerge as one of the most interesting compounds of the series) and that of 32, whose activity was limited to wt virus and unrelated to RT inhibiting properties. In line with these observations, the presence of a 6-(4fluorobenzyl) group led to the substantially inactive compounds 33 and 34 . On the basis of these results, we kept the 6-(2,6-dichlorobenzyl) substituent fixed and systematically modified the C-2 position. The 4-hydroxybenzyl group found in our lead compound 12c and also present in compound 24, did not positively contribute to the antiviral activity. Replacement of the $\mathrm{OH}$ group with $\mathrm{Br}, i \mathrm{Pr}$, and $\mathrm{CN}$ improved the general biological profile (compounds 23, 27, and 28), with activity ranging from 0.39 to $103 \mu \mathrm{M}$ in enzymatic tests, and from 0.79 to $0.17 \mu \mathrm{M}$ cells infected with wt virus. No interesting activity was observed on mutant strains, with the exception of 28, which retained activity on clinically relevant mutants at micromolar or submicromolar concentration. On the other hand, replacement of the $\mathrm{OH}$ group with $\mathrm{NO}_{2}$ led to the very interesting compound 15 (vide supra), whereas substitution of the $\mathrm{OH}$ group with alkoxy groups gave compounds $\mathbf{1 4}, \mathbf{2 5}$, and 26, whose activities were strongly dependent on the length of the alkyl moiety.

Thus, whereas 25 and 26 ( $p$-ethoxy and $p$-butoxy groups, respectively) were only moderately active on the wt, compound 14 ( $p$-methoxy) was endowed with very significant activity in the nanomolar range toward both wt and IRLL98 strains, as well as with low toxicity $(\mathrm{SI}>4600)$.

The contemporary presence on the aromatic ring of more than one methoxy group negatively affected the biological activity. A very marked improvement of the biological profile was obtained by increasing the length of the linker connecting the aromatic ring to the sulfur atom. Compounds 29 and 30 ( $n=2$ and 3, respectively) proved to be the most interesting among the new derivatives. In particular, 29 exhibited anti-HIV activity on cells infected with either wild-type or pluriresistant virus (IRLL98) at subnanomolar concentration, together with low cytotoxicity (SI > 410 000). On the whole, this compound showed an anti-HIV profile superior to that of nevirapine and comparable to that of efavirenz, thus emerging as the most active $S$ DABO analogue reported so far. Further lengthening of the linker led to compound $\mathbf{3 0}$ that, though retaining very good anti-HIV activity, was endowed with higher cytotoxicity. Finally, basically inactive compounds $(\mathbf{1 3}, \mathbf{3 7}$, and 38) were obtained by oxidation of the sulfur atom. Biological data showed some contradictions between $\mathrm{ID}_{50}$ and $\mathrm{EC}_{50}$ values for several compounds, probably due to the fact that cellular tests reflect the interference of a compound in 
viral steps not shown in the pure RT enzymatic tests (i.e., enzymatic tests account only for the DNA-RNA-dependent synthesis inhibition, whereas cellular test results represent the inhibition of all viral replication phases). Moreover, we cannot exclude the possibility that the low cellular activity or the inactivity of some of our compounds could be the consequence of poor adsorption through the T-cell membrane, in addition to a poor affinity for the corresponding receptor counterpart.

Table 3. Anti-HIV-1 activity and cytotoxicity of compounds 13-15, 23-36 and 37-38

\begin{tabular}{|c|c|c|c|c|c|c|c|c|}
\hline \multirow{2}{*}{ Cpd } & \multicolumn{3}{|c|}{$\mathrm{ID}_{50}(\mu \mathrm{M})^{a, b}$} & \multicolumn{4}{|c|}{$\mathrm{EC}_{50}(\mu \mathrm{M})^{a, c}$} & \multirow{2}{*}{$\mathrm{CC}_{50}^{d, b}$} \\
\hline & wt & $\mathrm{K} 103 \mathrm{~N}$ & Y181I & NL4-3 wt & IRLL98 & $\mathrm{K} 103 \mathrm{~N}$ & Y188L & \\
\hline 13 & 0.006 & 10 & 27 & $>2.8$ & $>2.8$ & $>2.8$ & $>2.8$ & 2.8 \\
\hline 14 & 0.004 & 102 & 150 & 0.007 & 0.047 & 4.7 & $>32$ & 32 \\
\hline 15 & 0.009 & 0.12 & 0.22 & 0.79 & 3.3 & 11 & $31 \%$ at $62^{e}$ & $>58$ \\
\hline 23 & 0.39 & 9 & $\mathrm{na}^{f}$ & 0.79 & $>53$ & $>53$ & $>53$ & 13 \\
\hline 24 & na & na & na & $>41$ & $>41$ & $>41$ & $>41$ & 41 \\
\hline 25 & 2 & na & na & 0.25 & 1.9 & $>58$ & $>58$ & $>58$ \\
\hline 26 & 2.8 & na & na & $>3.1$ & $34 \%$ at $11^{e}$ & $>3.1$ & $>3.1$ & 3.1 \\
\hline 27 & na & na & na & $35 \%$ at 2.3 & $>57$ & $>58$ & $>58$ & $45 \%$ at 11 \\
\hline 28 & 103 & na & na & 0.17 & 1.0 & 0.10 & $>60$ & $>60$ \\
\hline 29 & 0.026 & 3.2 & 1.5 & $<0.00044$ & 0.00022 & 0.87 & 6.9 & $>57$ \\
\hline 30 & 0.037 & 0.5 & 0.3 & 0.00044 & 0.11 & $>1.0$ & $>1.0$ & 1.0 \\
\hline 31 & 0.007 & 3.5 & na & 0.026 & 0.69 & 0.69 & 10 & $>64$ \\
\hline 32 & na & na & na & 0.074 & $>62$ & $>62$ & $>62$ & $>62$ \\
\hline 33 & na & na & na & $>65$ & $>65$ & $>65$ & $>65$ & $>65$ \\
\hline 34 & na & na & na & $>8.9$ & $>8.9$ & $>8.9$ & $>8.9$ & 8.9 \\
\hline 35 & 0.5 & na & na & 0.12 & 0.51 & 5.3 & 33 & $>57$ \\
\hline 36 & 3.5 & na & na & 13 & $>48$ & $>48$ & $>48$ & $>48$ \\
\hline 37 & na & na & na & $>53$ & $>53$ & $>53$ & $>53$ & $>53$ \\
\hline 38 & na & na & na & $>50$ & $>50$ & $>50$ & $>50$ & $>50$ \\
\hline nev & 0.4 & 8 & 20 & 0.052 & $>7.5$ & 3.9 & $>7.5$ & $>7.5$ \\
\hline efa & 0.04 & 0.4 & 0.1 & 0.001 & 0.2 & 0.057 & 0.3 & $>0.32$ \\
\hline azt & & & & 0.003 & 0.008 & 0.003 & 0.003 & 3.7 \\
\hline
\end{tabular}

${ }^{a}$ Data represent mean values of at least two experiments.

${ }^{b} \mathrm{ID}_{50}$ : inhibiting dose 50 or needed dose to inhibit $50 \%$ of enzyme.

${ }^{c} \mathrm{EC}_{50}$ : effective concentration 50 or needed concentration to inhibit 50\% HIV-induced cell death, elevated with MTT method in MT-4 cells.

${ }^{d} \mathrm{CC}_{50}$ : cytotoxic concentration 50 or needed concentration to induce $50 \%$ death of non-infected cells evaluated with the MTT method in MT-4 cells.

${ }^{e}$ Percent inhibition of HIV-induced cell death at the reported micromolar concentration.

${ }^{f}$ na: not active at $400 \mu \mathrm{M}$ (the highest concentration tested). 
To investigate the binding mode of these new NNRT inhibitors, molecular-docking simulations were performed by means of the software Autodock. Results showed how $\mathbf{1 4}$ assume an orientation very similar to that of the cocrystallized inhibitor (MKC-442, emivirine). In particular, the pyrimidinone ring of 14 was superposable to that of MKC-442, allowing for a hydrogen-bond contact between its NH group at position 3 with the carbonyl moiety of Lys 101 (1.9 $\AA$ ), suggested to be a crucial interaction key for inhibitors belonging to the DABO and $S$ DABO classes of compounds. ${ }^{50}$ Moreover, the side chains of both Lys103 and Val106 were also found at close contact with the pyrimidinone nucleus. The extended side chains at position 2 of both 14 and MKC-442 were lined up in a parallel way and pointed toward the solvent accessible surface defined by Pro225 and Pro236.
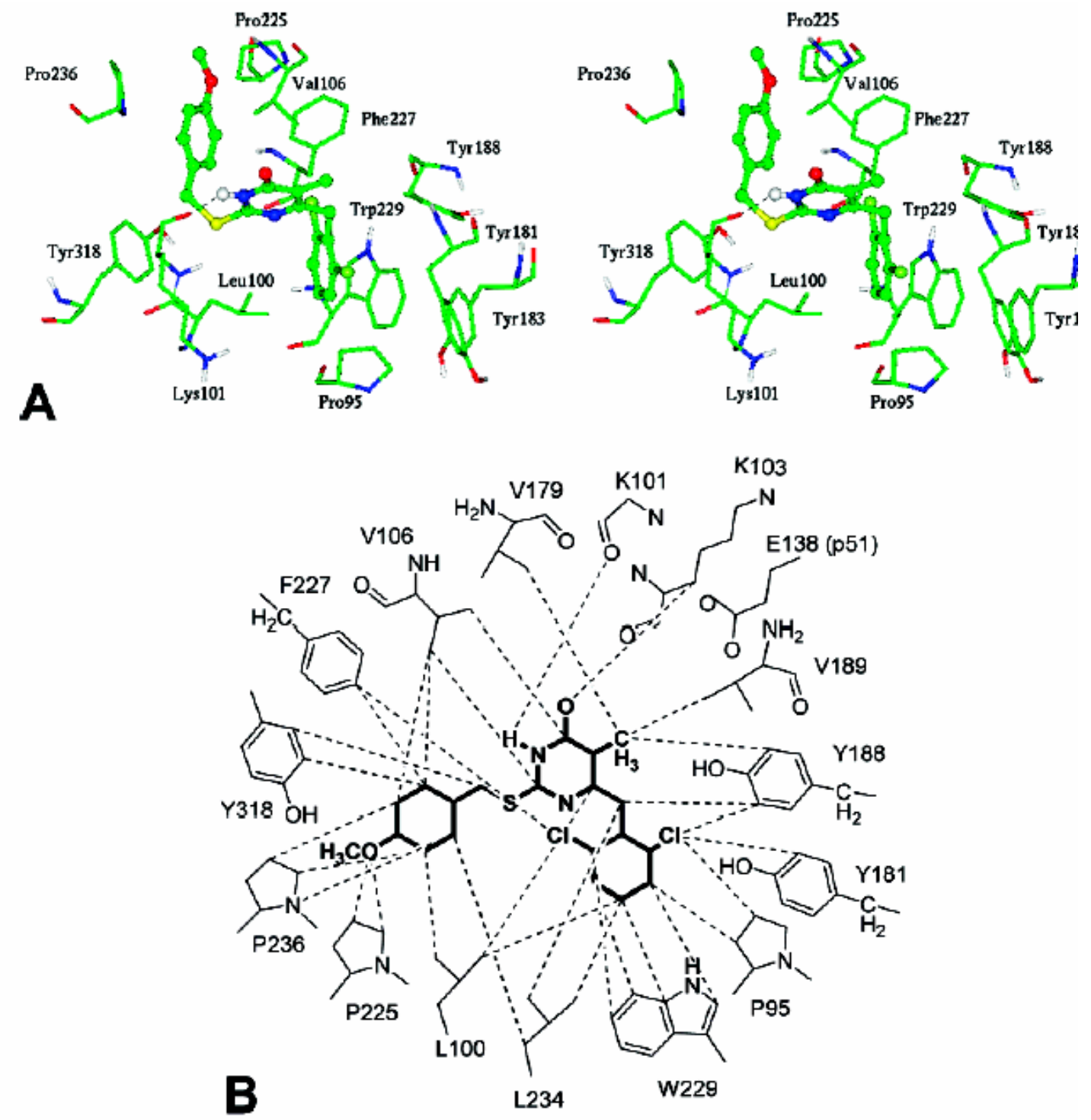

Figure 7. Stereographic (A, the inhibitor shown in ball-and-stick notation) and schematic (B, the inhibitor drawn with thick lines) representations of the orientation mode of compound 14 into the 
NNIBP. The terminal methyl group of the side chain at position 2 contacts both Pro225 and Pro236 at the surface of RT. Moreover, the 3-NH group of the pyrimidinone ring is involved in a hydrogen-bond interaction with the carbonyl oxygen of Lys101. Finally, the benzyl chain at position 6 is accommodated within a large pocket mainly defined by the hydrophobic side chains of Leu100, Trp229, Phe227, Tyr181, Tyr183, and Tyr188. For sake of clarity, only representative amino acids are shown.

In further detail, although the sulfur atom of $\mathbf{1 4}$ was located at a distance of about $3.7 \AA$ from the backbone-NH group of Lys101, the benzyl moiety was accommodated into a large pocket mainly defined by Val106, Pro225, Pro236, and Tyr318 (Figure 7). Good profitable hydrophobic interactions were found between the alkyl side chain of Val106 and the phenyl ring of the inhibitor as well as between the terminal methyl group with both Pro225 and Pro236. Finally, the benzyl substituent at position 6 of $\mathbf{1 4}$ was embedded into an extended hydrophobic region defined by the aromatic side chains of Tyr181, Tyr188, Phe227, and Trp229 as well as by Leu100 and Leu234. The major difference between the experimental and calculated complexes involved the interaction between the 6-benzyl side chain of the inhibitors and the side chain of Trp229. In fact, although a T-tilted interaction was shown in the complex with MKC-442, a $\pi-\pi$ interaction was found in the complex with $\mathbf{1 4}$. This was mainly due to the fact that a significant conformational rearrangement occurred within the aromatic cage accommodating the substituent at position 6. In fact, the aromatic side chains of Tyr183, Tyr188, and Trp229 approached the inhibitor, leading to a structural system where the indole nucleus was sandwiched between the 6benzyl group of the inhibitor and the phenyl ring of Tyr183 (allowing $\pi-\pi$ interactions) and interacted with a T-tilted contact with the aromatic moiety of Tyr188. On the other hand, although Phe 227 retained its original position, a rotation of the Tyr181 side chain occurred pushing it about $1.8 \AA$ away from the NNIBP. Similar results were found for the nitro derivative 15, with a major difference involving the benzylthio side chain that was located in a region of space comprised between the corresponding side chain of $\mathbf{1 4}$ and the N1 side chain of the crystallized inhibitor. In particular, due to a rotation of about $20^{\circ}$ around the C2-S bond, the nitro group was inserted between Pro225 and the side chain of Phe227, and one of its electron-rich oxygen atoms was found at the proper distance (1.6 ̊) to make a hydrogen-bond contact with the backbone-NH group of Phe227. Lengthening the benzyl moiety of 14 to a phenylethyl (29) and phenylpropyl (30) chain led their $p$-methoxy group to go beyond the opening defined by Pro225 and Pro236 and, thus, to be exposed to the solvent. Moreover, such a shift of the phenyl ring caused the lack of its hydrophobic interactions with the side chain of Val106. The pyrimidinone nucleus of $\mathbf{3 0}$ maintained an orientation comparable to that of 14, including the hydrogen-bond contact with Lys 101 as well as the hydrophobic interactions with a part of the Val106 side chain. Similarly, no substantial difference was found for the location of the benzyl substituent at position 6 , in comparison to that of $\mathbf{1 4}$ and the crystallized inhibitor. On the other hand, the 6-benzylpyrimidinone system of $\mathbf{2 9}$ underwent a significant conformational rearrangement, allowing for a hydrogen-bond contact involving the carbonyl oxygen and the 
backbone-NH group of Lys101, in addition to the hydrogen-bond contact between the 3-NH group of the inhibitor and the carbonyl of the same amino acid. Moreover, due to the fact that the benzyl group at the position 6 was characterized by an alternative orientation into the hydrophobic cage previously described, the profitable aromatic-aromatic interaction involving the side chain of Trp229 was lost. In summary, docking calculations suggested that the $p$ methoxybenzylthio group at position 2 of $\mathbf{1 4}$ seems to be characterized by the optimal length to fulfill the tunnel delimited, at the surface of the RT structure, by Pro225 and Pro236. Moreover, the lower activity of $\mathbf{2 9}$ and $\mathbf{3 0}$ toward the wt RT, with respect to that of their shorter analogue 14, was in part due to reduced hydrophobic interactions mainly involving the benzyl substituents at position 2 as well as to unfavorable contacts between the terminal methyl substituent and the solvent. In a similar way, analogues of $\mathbf{1 4}$, bearing at the para position of the 2-benzyl substituent a hydrophobic group larger than a methoxy moiety (exceeding the surface of the RT and contacting the solvent), showed lower activity than 14. In fact, the ethoxy, butoxy, and isopropyl derivatives $(\mathbf{2 5}, \mathbf{2 6}$, and 27) showed activity in the micromolar range or lower.

\subsection{Parallel solution phase synthesis of 2-methylsulfonyl-4-dialkylamino-6-vinyl pyrimidines}

Another series of biologically interesting compounds was obtained starting from an empirical observation made during previous studies. Looking for a cleavage procedure for the synthesis of 2-aminopyrimidine derivatives, compound 39 was initially oxidized to the corresponding sulfone 40 by reaction with $\mathrm{Oxone}^{\circledR}$ in a $1: 1$ mixture of $\mathrm{MeOH} / \mathrm{H}_{2} \mathrm{O}$ (Scheme 5). However, the subsequent nucleophilic displacement of the sulfone moiety with pyrrolidine at $80^{\circ} \mathrm{C}$ gave compound $\mathbf{4 1}$ instead of the expected compound $\mathbf{4 2 .}$

The formation of $\mathbf{4 1}$ was explained assuming that the sulfone moiety might confer Michael acceptor properties to the vinyl group of 40: in fact, reacting compound 39 with pyrrolidine at $80^{\circ} \mathrm{C}$, neither displacement nor addition reaction occurred. This observation suggests that 6-vinyl activated derivatives could give interesting interaction with basic amino acid residues into the HIV-1 RT non nucleoside binding site. 


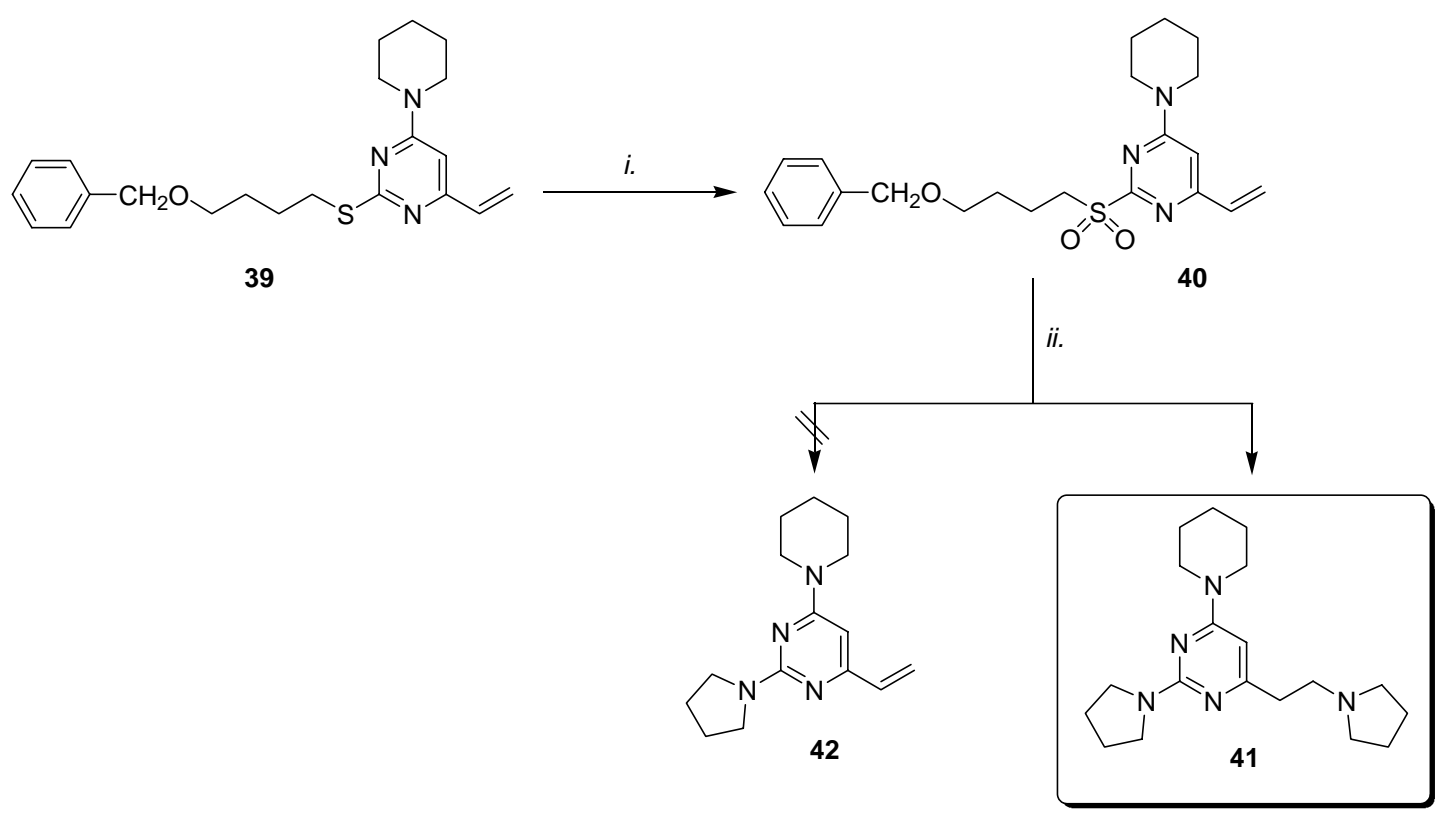

Scheme 5. $i$. Oxone, $\mathrm{H}_{2} \mathrm{O}, \mathrm{MeOH}$, rt, overnight; ii. pyrrolidine, dioxane, $80^{\circ} \mathrm{C}$, overnight.

We decided therefore, to develop a methodology for the parallel solution-phase synthesis of pyrimidine derivatives bearing both the 6-vinyl and 2-methylsulfonyl moieties and to explore first the modification of $\mathrm{C}-4$ position using different amines, according to a previously reported procedure. $^{53}$

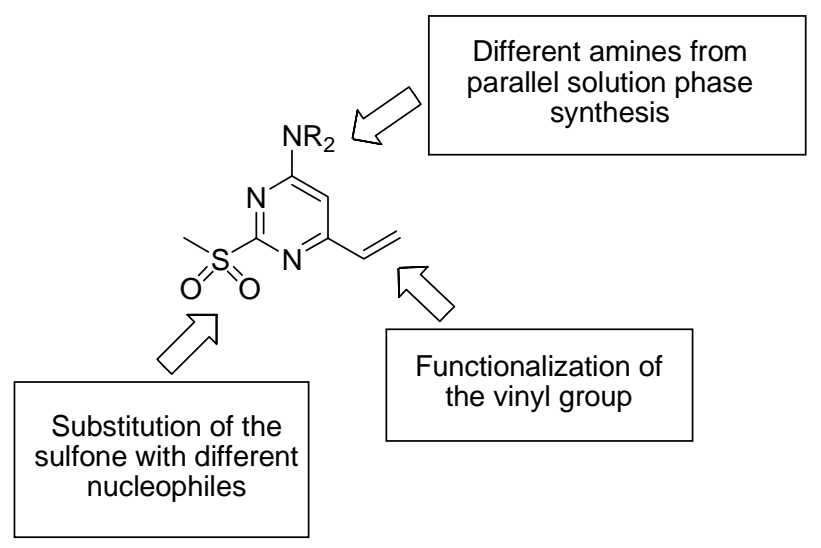

Figure 8. Further functionalizations of 2-methylsulfonyl-6-vinylpyrimidines.

This approach would lead eventually to a general core structure suitable for further lead optimization (Figure 8): the 6-vinyl group could be functionalized by alkylation reactions, epoxidation followed by ring opening, Diels-Alder reactions, and so on, while the 2methylsulfonyl moiety could ideally be substituted with different nucleophiles. 
For the synthesis of target compounds 48a-k, the approach described in Scheme 6 was initially followed, ${ }^{54}$ essentially based on the activation of the alcohol moiety of pyrimidinone $\mathbf{4 5}$ followed by nucleophilic displacement of the activated hydroxy group with a series of different amines.<smiles>CCOC(=O)CC(=O)CC(C)C</smiles>

43<smiles>C#CC[Se-]CCc1cc(=O)[nH]c(SC)n1</smiles>

46

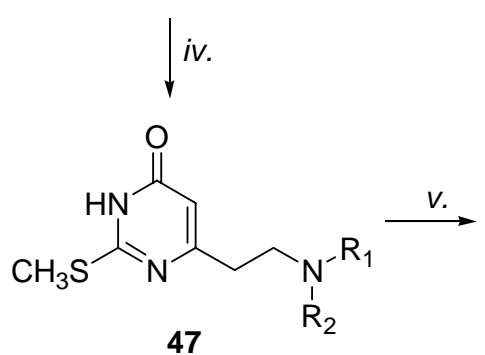<smiles>CCOC(=O)Cc1cc(=O)[nH]c(SC)n1</smiles>

iii.<smiles>CSc1nc(CCO)cc(=O)[nH]1</smiles>

45<smiles>[R]N([R])c1cc(C=C)nc(S(=O)O)n1</smiles>

Scheme 6. Reagents and conditions: $i$. S-methylisothiourea sulfate, $\mathrm{Ca}(\mathrm{OH})_{2}, \mathrm{H}_{2} \mathrm{O} / \mathrm{EtOH} ; i$. $\mathrm{LiAlH}_{4}$, THF; iii. TsCl, DMAP, $\mathrm{CH}_{2} \mathrm{Cl}_{2} ; i v$. $\mathrm{R}_{1} \mathrm{R}_{2} \mathrm{NH}$, THF, reflux; v. (a) $\mathrm{NaH}$, dioxane, reflux; (b) Oxone ${ }^{\circledR}, \mathrm{H}_{2} \mathrm{O}, \mathrm{MeOH}$.

A deeper analysis of IR and NMR spectra of compound $\mathbf{4 6}$ raised the doubt about its real structure even if a previously detailed job ${ }^{54-55}$ assigned the structure drawn in Scheme 6. In our mind, the tosylation reaction was more likely to be occurred on the $\mathrm{C}-4 \mathrm{OH}$ rather than on the primary hydroxy group as initially supposed. Finally, X-Ray crystallographic analysis of $\mathbf{4 6}$ (Figure 9) confirmed this assumption; definitely assigning to the tosyl derivative the structure $\mathbf{4 9}$ (Scheme 7). As a result, all compounds previously synthesized ${ }^{53-55}$ have the general structure $\mathbf{5 0}$ instead of 47 (Figure 10). ${ }^{56}$ 


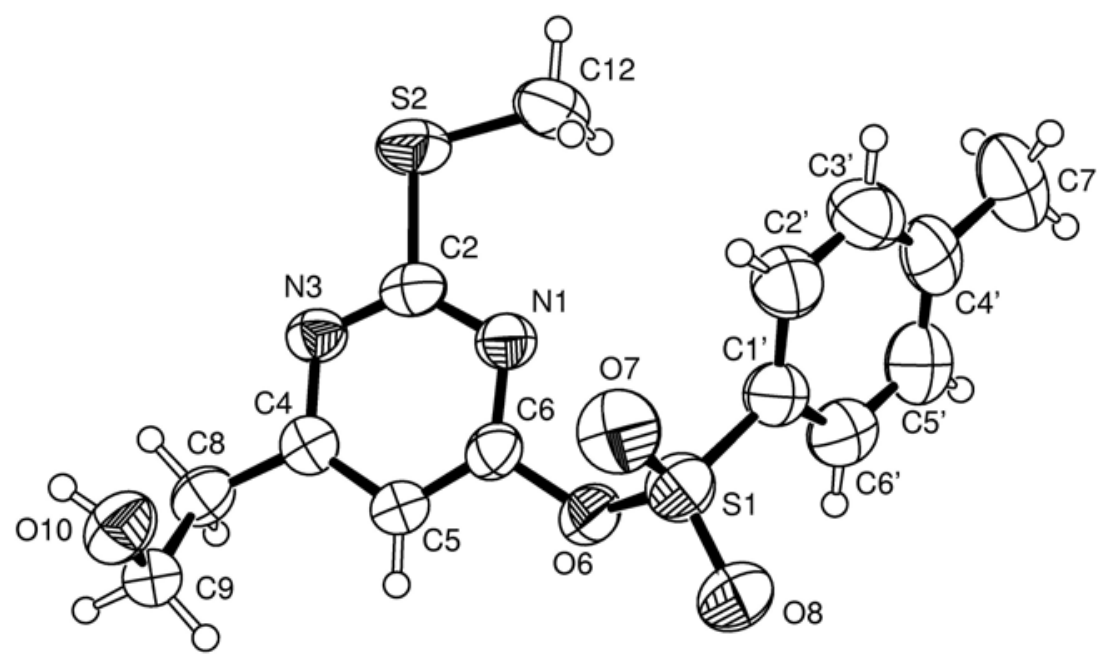

Figure 9. Drawing of the crystal structure of compound 49. Ellipsoids enclose $50 \%$ probability.

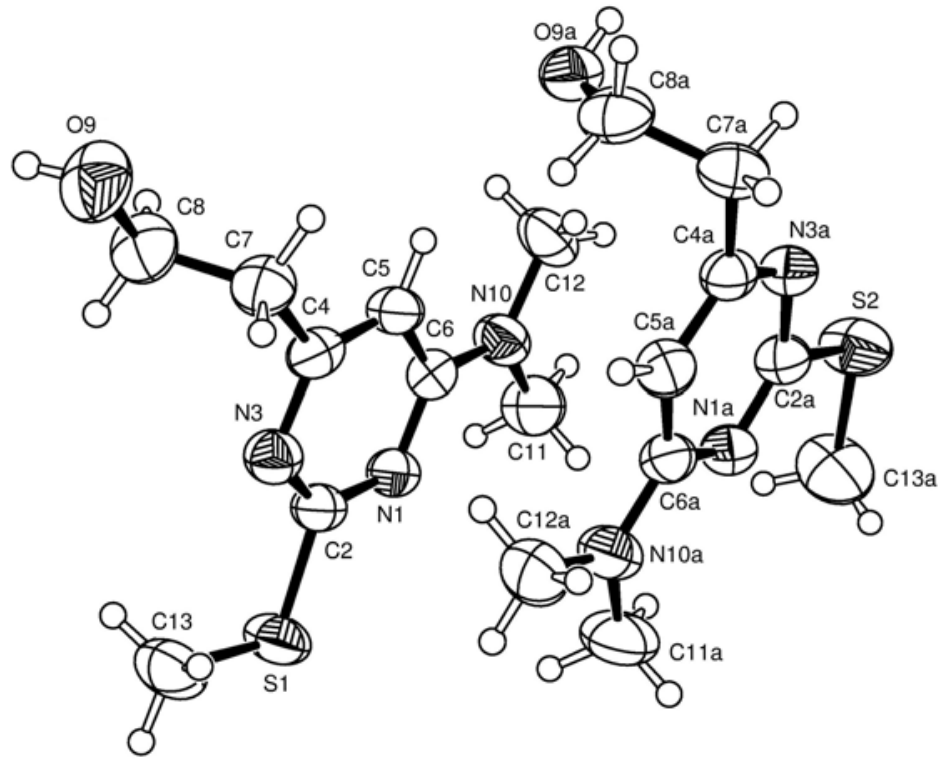

Figure 10. Drawing of the crystal structure of compound 50a. Ellipsoids enclose 50\% probability.

Having established the correct structure of reaction intermediates we decided, therefore, to develop a methodology for the solution-phase parallel synthesis of pyrimidine derivatives bearing both the 6-vinyl and 2-methylsulfonyl moieties and to introduce, in the first instance, a single variation in $\mathrm{C}-4$ position using different amines, according to reinvestigated procedure.

As the starting material for our synthesis, we prepared tosylate 49 (Scheme 7) according to the previously developed procedure ${ }^{53}$ and which was further optimized by performing the 
tosylation reaction under microwave-assisted conditions. In this way, $\mathbf{4 9}$ could be obtained in only $6 \mathrm{~min}$ instead of the $24 \mathrm{~h}$ required by the original procedure.
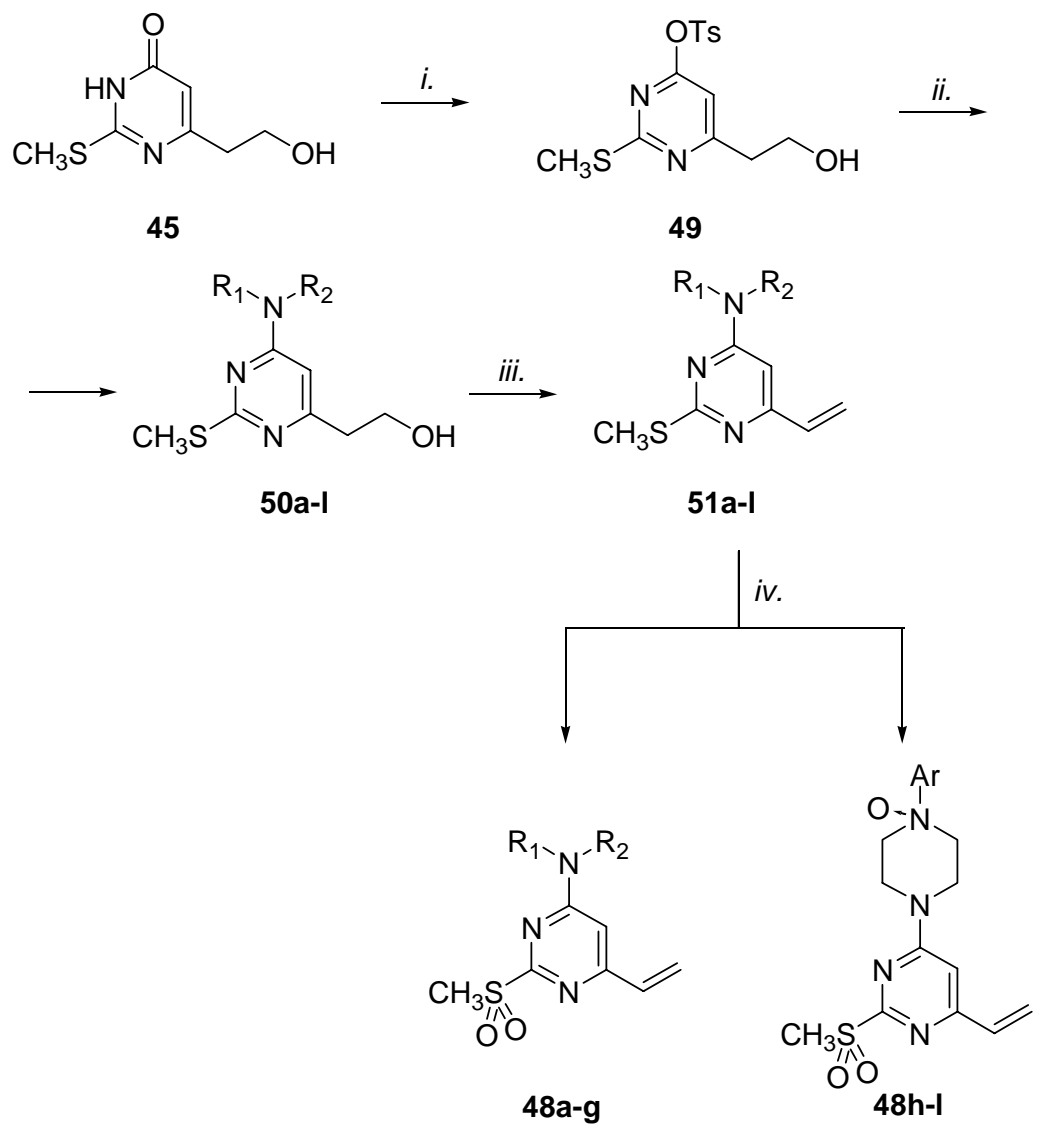

Scheme 7. Reagents and conditions: $i$. TsCl, DMAP, $\mathrm{CH}_{2} \mathrm{Cl}_{2}, \mathrm{MW}, 50^{\circ} \mathrm{C}, 6 \mathrm{~min}$; ii. (a) $\mathrm{R}_{1} \mathrm{R}_{2} \mathrm{NH}$, THF, reflux, 360 rpm, overnight; (b) PS-1,3,4,6,7,8-hexahydro-2H-pyrimido[1,2-a]-pyrimidine; (c) PS-isocyanate; iii. $\mathrm{NaH}$, dioxane, reflux, $360 \mathrm{rpm}, 3 \mathrm{~h}$; iv. Oxone, $\mathrm{H}_{2} \mathrm{O}, \mathrm{MeOH}, \mathrm{rt}, 360 \mathrm{rpm}$, $3 \mathrm{~h}$.

The tosyl derivative 49 was then submitted to a three-step parallel solution phase procedure using a Büchi Syncore Synthesizer. In the first step, compound $\mathbf{4 9}$ was partitioned into 11 separate reaction vessels and then reacted with 11 different amines in a 2-fold excess in order to drive the reactions to completion. Once HPLC analysis revealed that all the reactions were finished, two solid-supported scavengers for nucleophiles were added to remove excess reagents and side products. The PS-1,3,4,6,7,8-hexahydro- $2 H$-pyrimido[1,2- $a$ ]pyrimidine scavenger was added to bind the $p$-toluensulfonic acid released in the reaction medium as side product, while the excess of secondary amines was removed using a PS-isocyanate scavenger. After simple parallel filtration, compounds 50a-k were obtained in more than 95\% purity, as shown by HPLC/MS analysis. Compounds 50a-k were then treated with $\mathrm{NaH}$ in refluxing dioxane. After removing volatiles under reduced pressure, the reaction mixtures were taken up in $\mathrm{CH}_{2} \mathrm{Cl}_{2}$ and 
subjected to parallel filtration to afford compounds 51a-k as pure products. Finally, compounds 51a-k were converted into corresponding sulfones 48a-k, without undesired epoxidation of the vinyl group, by treatment with Oxone ${ }^{\circledR}$, which has proven to be very efficient for selective sulfur oxidation. ${ }^{34}$ However, while compounds 51a-g were transformed into the corresponding sulfones 48a-g after $3 \mathrm{~h}$ at room temperature and were obtained as pure products after ethyl acetate extraction, compounds 51h-k, containing a phenylpiperazino moiety at the C-4 position, upon treatment with Oxone ${ }^{\circledR}$ gave compounds $\mathbf{4 8 h}-\mathbf{k}$, resulting from overoxidation of the piperazine nitrogen directly bound to the nonheterocyclic aromatic ring. Interestingly, only the nitrogen linked to the nonetherocyclic ring gives rise to the corresponding $N$-oxide, because no overoxidation product formed on treatment of $\mathbf{5 1 g}$ with Oxone ${ }^{\circledR}$. Since the $N$-oxide derivatives proved to be very polar compounds, it was hard to obtain them as pure products by simple extraction, and chromatographic purification was required to obtain pure $\mathbf{4 8 h}-\mathbf{k}$ in good yield (Table 4). All the synthesized compounds were submitted to biological evaluation as HIV-1 RT inhibitors according to a previously described procedure. ${ }^{54}$ Compounds $48 \mathbf{a}$ and $\mathbf{4 8 b}$ were proved to inhibit the wild type $\mathrm{RT}$ with $\mathrm{nM}$ and $\mu \mathrm{M}$ potency, respectively, acting with a new competitive mechanism never reported in the literature for this class of compounds. ${ }^{57,58}$ However, details of this mechanism remain still unknown.

Computational studies were carried out on compound 48a-c (Figure 11) in order to rationalize the significant activity of $\mathbf{4 8} \mathbf{a}^{58}$ against wild-type RT and the loss of activity observed for 48c.

To perform a comparative study, compounds 48a-c were docked in the wild-type RT of HIV-1 binding pocket starting with coordinates from the X-ray structure of the TNK-651/HIVRT complex (pdb code 1rt2). As shown in Figure 12, the binding mode of both compound 48a and 48b place the sulfone group oriented towards the Lys-101 and Lys-103 terminal amino groups. However, a major difference in the orientation of these two compounds comes from the orientation of the $\mathrm{C} 4$ dialkylamino group: the diethylamino group of $\mathbf{4 8 b}$ is not oriented towards Trp-229 (as observed for the dimethylamino group of 48a) but towards the Lys-101 backbone, probably to relieve unfavorable steric interactions with Trp-229. Despite this different orientation into the binding site, both compounds $\mathbf{4 8 a}$ and $\mathbf{4 8 b}$ retain the most important stabilizing interactions, such as $\pi-\pi$ contacts between the ligand and Tyr-181, Tyr-188 and Phe-227. 
Table 4. Chemical and biological data of derivatives 48a-k

\begin{tabular}{|c|c|c|c|}
\hline Compd & $\mathrm{R}_{1} \mathrm{R}_{2} \mathrm{NH}$ & Yield $(\%)$ & $\mathrm{ID}_{50}(\mu \mathrm{M})$ \\
\hline 48a & & 83 & 0.003 \\
\hline $48 b$ & & 93 & 11.6 \\
\hline $48 c$ & & 95 & na \\
\hline 48d & & 95 & 160 \\
\hline $48 \mathrm{e}$ & & 92 & 1800 \\
\hline $48 f$ & & 90 & 1800 \\
\hline $48 g$ & & 90 & 322 \\
\hline $48 \mathrm{~h}$ & & 82 & 750 \\
\hline $48 \mathrm{i}$ & & 88 & na \\
\hline $48 j$ & & 87 & 640 \\
\hline $48 \mathrm{k}$ & & 80 & 1700 \\
\hline
\end{tabular}

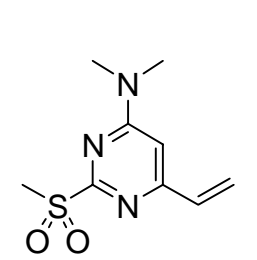

$48 a$

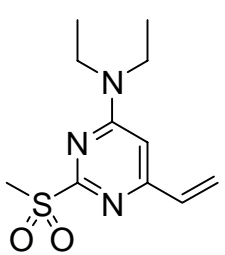

$48 b$

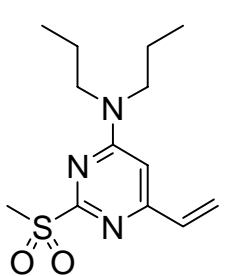

48c

Figure 11. Compounds subjected to docking studies. 
a

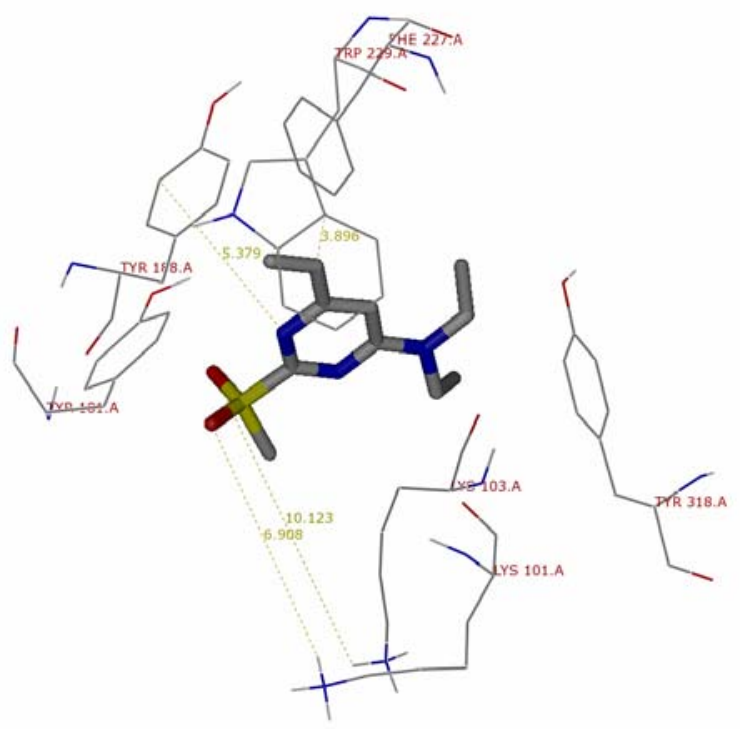

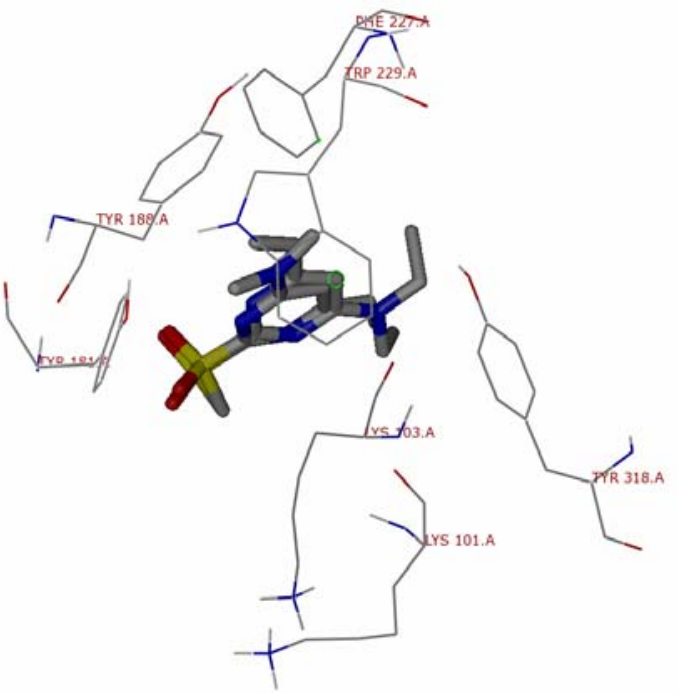

b

Figure 12. (a) Docking of compound 48b on the NNBP (wild-type HIVRT). (b) Superposition of the preferred docked conformations of compounds $48 \mathrm{a}$ and $\mathbf{4 8 b}$ in the wild-type HIVRT.

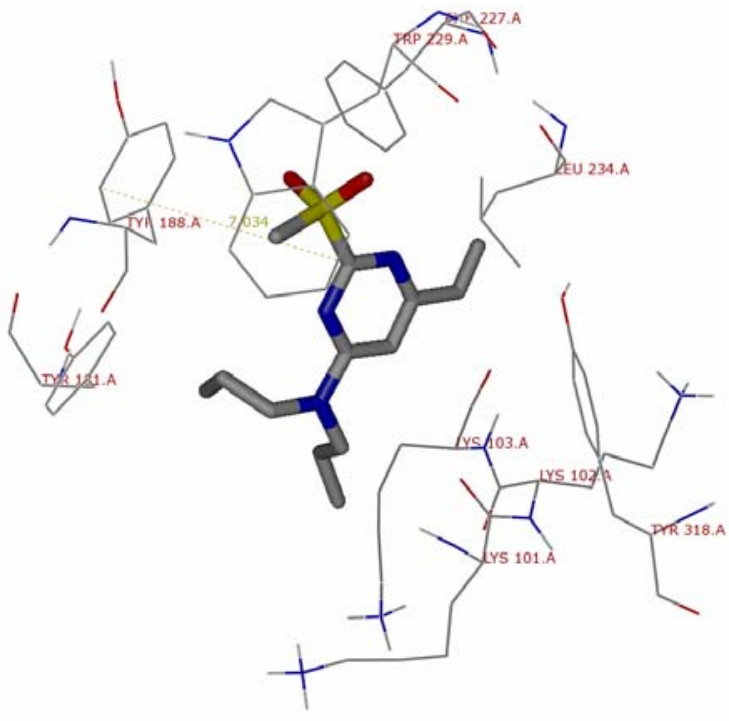

a

Figure 13. (a) Docking of compound 48c on the NNBP (wild-type HIVRT). (b) Superposition of the preferred docked conformations of compounds $\mathbf{4 8 a}, \mathbf{4 8 b}$ and 48c in the wild-type HIVRT.

Another different binding mode was found from the docking of compound 48c (Figure 13). The bigger dipropylamino group causes the ligand to reorient in the binding site, so that this bulky group become oriented towards Lys-101 and Lys-103, probably to relieve steric 
interactions with Trp-229 and the Lys-101-backbone. In the preferred docked conformation of 48c, the important stabilizing interactions observed for 48a and 48b are no more present and this could explain the 1000 fold loss of activity seen for compound $\mathbf{4 8 c} .^{57}$

\section{Conclusions}

In conclusion, the present work highlights the importance of modern combinatorial and microwave assisted techniques in the process of drug discovery. Starting from the solid supported compounds 4a-c, 8a-d and 9a-d, it has been possible to generate six types of pyrimidinone derivatives $(5,6,7, \mathbf{1 0}, \mathbf{1 1}, \mathbf{1 2})$ bearing different substituent on $\mathrm{C} 2, \mathrm{C} 5$ and $\mathrm{C} 6$. Subsequent biological evaluations brought to the identification of the lead compound 12c as moderate HIV-1 RT inhibitor. Based on 12c, a small virtual combinatorial library was designed and generated to suggest the synthesis of further derivatives. Using parallel solution-phase and microwave-assisted techniques, a focused library of $31 \mathrm{~S}$-DABO derivatives was synthesized. Results from anti-HIV reverse transcriptase assays and anti-HIV activity in lymphoid cells showed activity values in the nanomolar and subnanomolar range for the best derivatives. Moreover, one of the new compounds (31) was characterized by an anti-HIV profile better than that of nevirapine and comparable to that of efavirenz, thus emerging as the most active $S$-DABO analogue reported so far.

Finally a simple and efficient parallel solution-phase methodology for the synthesis of 2,4,6-trisubstituted pyrimidine derivatives 48a-k was developed. By means of this procedure, a set of secondary amines (dialkylamines, diallylamines, benzylamines, and substituted piperazines) was introduced into the $\mathrm{C}-4$ position of the pyrimidine moiety in only one synthetic step. Biological evaluation of these compounds led us to the discovery of two interesting competitive RT inhibitors (48a and $\mathbf{4 8 b}$ ) which mechanism of action remains still unknown.

\section{Acknowledgements}

This study was partially supported by grants from the European TRIoH Consortium (LSHB2003-503480), M.B. thanks Dr. Paolo Malizia for support in the earlier times of his career.

\section{References}

1. Anzali, S.; Barnickel, G.; Cezzanne, B.; Krug, M.; Filimonov, D.; Porolkov, V. J. Med. Chem. 2001, 44, 2432.

2. Walters, W:P.; Stahl, M. T.; Murcko, M. A. Drug Discov. Today 1998, 3, 160.

3. Ganesan, A. Drug Discov. Today 2002, 7, 47.

4. Chiosis, G.; Boneca, I. G. Science 2001, 293, 1484. 
5. Macdonald, S. J.; Dowle, M. D.; Harrisono, L. A.; Inglis, G. G.; Johnson, M. R.; Shah, P.; Smith, R. A.; Amour, A.; Fleetwood, G. J. Med. Chem. 2002, 45, 3878.

6. Edwards, P. Drug Disc. Today 2003, 8, 762.

7. He, Y.; Chen, F., Yu, X.; Wang, Y.; De Clercq, E.; Balzarini, J.; Pannecouque, C. Bioorg Chem. 2004, 32, 536.

8. Botta, M.; De Angelis, F.; Nicoletti, R. Tetrahedron Lett. 1988, 29, 2741.

9. Baba, M.; Tanaka, H.; De Clercq, E.; Pauwels, R.; Balzarini, J.; Schols, D.; Nakashima, H.; Perno, C.-F.; Walzer, R. T.; Miyasaka, T. Biochem. Biophys. Res. Commun. 1989, 165, 1375.

10. Ludovici, D. W.; Kavash, R. W.; Kukla, M. J.; Ho, C. Y.; Ye, H. Bioorg. Med. Chem. Lett. 2001, 11, 2229.

11. Das, K.; Clark, A. D. Jr.; Lewi, P. J.; Heeres, J.; De Jonge, M. R.; Koymans, L. M. H.; Vinkers, H. M.; Daeyaert, F.; Ludovici, D. W.; Kukla, M. J.; De Corte, B.; Kavash, R. W.; Ho, C. Y.; Ye, H.; Lichtenstein, M. A.; Andries, K. R.; Pauwels, R.; De Béthune, M. P.; Boyer, P. L.; Clark, P.; Hughes, S. H.; Janssen, P. A. J.; Arnold, E. J. Med. Chem. 2004, 47, 2550.

12. Guillemont, J.; Pasquier, E.; Palandjian, P.; Vernier, D.; Gaurrand, S.; Lewi, P. J.; Heeres, J.; De Jonge, M. R.; Koymans, L. M. H.; Daeyaert, F. F. D.; Vinkers, M. H.; Arnold, E.; Das, K.; Pauwels, R.; Andries, K.; De Béthune, M. P.; Bettens, E.; Hertogs, K.; Wigerinck, P.; Timmerman, P.; Janssen, P. A. J. J. Med. Chem. 2005, 48, 2072.

13. Bher, J.-B.; Gourlain, T.; Helimi, A.; Guillerm, G. Bioorg. Med. Chem. Lett. 2003, 13, 1713.

14. Nayyar, A.; Jain, R. Curr. Med. Chem. 2005, 12, 1873.

15. Langer, C.; Dansker, J.; Ridgo, A. Clin. Adv. Hematol. Oncol. 2003, 1, 424.

16. Smaniotto, D.; D’Agostino, G.; Luzi, S.; Valentini, V.; Macchia, G.; Mangiacotti, M. G.; Margoriti, P. A.; Ferrandiono, G.; Scambia, G. Tumori 2005, 91, 215.

17. Faludi, G. Neuropsychopharmacol Hung. 2005, 7, 22.

18. Lieberman, J. A.; Stroup, T. S.; McEvoy, J. P.; Suartz, M. S.; Rosenheck, R. A.; Perkins, D. O.; Keefe, R. S.; Davis, S. M.; Davis, C. E.; Lebowitz, B. D.; Severe, J.; Hsiao, J. K. N. Engl. J. Med. 2005, 353, 1209.

19. Bher, J.-B.; Gourlain, T.; Helimi, A.; Guillerm, G. Bioorg. Med. Chem. Lett. 2003, 13, 1713.

20. Saladino, R.; Ciambecchini, U; Maga, G.; Mastromarino, P.; Conti, C.; Botta, M. Bioorg. Med. Chem. 2002, 10, 2143.

21. Kramer, A.; Horn, H. W.; Rice, J. E. J. Comput. Aided Mol. Des. 2003, 17, 13.

22. Bruno-Blanch, L.; Galvez, J.; Garcia-Domenech, R. Bioorg. Med. Chem. Lett. 2003, 13, 2749.

23. Kappe, C. O. Curr. Opin. Chem. Biol. 2002, 6, 314.

24. Nizi, E.; Botta, M.; Corelli, F.; Manetti, F.; Messina, F.; Maga, G. Tetrahedron Lett. 1998, 39, 3307.

25. Botta, M.; Corelli, F.; Maga, G.; Manetti, F.; Renzulli, M.; Spadari, S. Tetrahedron 2001, $57,8357$. 
26. Mugnaini, C.; Petricci, E.; Corelli, F.; Botta, M. Comb. Chem. High Through. Screen. 2005, $8,387$.

27. Botta, M.; Cavalieri, M.; Ceci, D.; De Angelis, F.; Finizia, G.; Nicoletti, R. Tetrahedron 1984, 40, 3313.

28. Botta, M.; Occhionero, F.; Nicoletti, R.; Mastromarino, P.; Conti, C.; Magrini, M.; Saladino, R. Bioorg. Med. Chem. 1999, 7, 1925.

29. Ragan, J.; Breitfelder, S.; Cirillo, P.; Gilmore, T.; Graham, A. G.; Hickey, E.; Klaus, B.; Madwed, J.; Moriak, M.; Moss, N. J. Med. Chem. 2002, 45, 2994.

30. Dolle, R. J. Comb. Chem. 2002, 4, 369.

31. Balkenhohl, F.; Bussche-Hünnefeld, C.; Lansky, A.; Zechel, C. Angew. Chem. Int. Ed. Eng. 1996, 35, 2288.

32. Haslam, E. Shikimic Acid Metabolism and Metabolites, Wiley \& Sons: New York, 1993.

33. Dal Cin, M.; Davalli, S.; Marchioro, C.; Passarini, M.; Perini, O.; Provera, S.; Caramella, A. Il Farmaco 2002, 57, 497.

34. Shapiro, M.J.; Gounarides., J.S. Prog. Nucl. Mag. Res. Sp. 1999, 35, 153.

35. Green., T.W. In Protective Groups in Organic Synthesis, Wiley-Interscience: New York, 1980, pp 193-287.

36. Kundu, N.G.; Das, B.; Majamdar, A. Synthesis 1990, 243.

37. Radi, M. Master Thesis, University of Siena, 2000.

38. Young, R.N.; Gauthier, J.Y.; Coombs., W. Tetrahedron Lett. 1984, 25, 1753.

39. Kumar, A.; Sinha, S.; Chauhan., P.M.S. Bioorg. Med. Chem. Lett. 2002, 12, 667.

40. Webb., K.S. Tetrahedron Lett. 1994, 35, 3457.

41. Petricci, E.; Renzulli, M.; Radi, M.; Corelli, F.; Botta, M. Tetrahedron Lett. 2002, 43, 9667.

42. Botta, M.; Corelli, F.; Petricci, E.; Seri, C. Heterocycles 2002, 56, 369.

43. Petricci, E.; Botta, M.; Corelli, F.; Mugnaini, C. Tetrahedron Lett. 2002, 43, 6507.

44. Petricci, E.; Mugnaini, C.; Radi, M.; Corelli, F.; Botta , M. J. Org. Chem. 2004, 69, 7880.

45. Parlato, M. C.; Mugnaini, C.; Renzulli, M. L.; Corelli, F.; Botta, M. Arkivoc 2004, V, 349.

46. Mai, A.; Artico, M.; Sardella, G.; Massa, S.; Novellino, E.; Greco, G.; Loi, A. G.; Tramontano, E.; Marongiu, M. E.; La Colla, P. J. Med. Chem. 1999, 42, 619.

47. Clay, R. J.; Collom, T. A.; Karrick, G. L.; Wemple, J. A. Synthesis 1993, 290.

48. Manetti, F.; Esté, J. A.; Closet-Codina, I.; Armand-Ugón, M.; Maga, G.; Crespan, E.; Cancio, R.; Mugnaini, C.; Bernardini, C.; Togninelli, A.; Carmi, C.; Alongi, M.; Petricci, E.; Massa, S.; Corelli, F.; Botta, M. J. Med. Chem. 2005, 48, 8000.

49. Togninelli, A.; Carmi, C.; Petricci, E.; Mugnaini, C.; Massa, S.; Corelli, F.; Botta, M. Tetrahedron Lett. 2005, 47, 65.

50. Mai, A.; Artico, M.; Ragno, R.; Sbardella, G.; Massa, S.; Musiu, C.; Mura, M.; Marturana, F.; Cadeddu, A.; Maga, G.; La Colla, P. Bioorg. Med. Chem. 2005, 13, 2065, and references therein.

51. Botta, M.; Corelli, F.; Petricci, E.; Radi, M. Unpublished results.

52. Font, D.; Heras, M. J. Comb. Chem. 2003, 5, 311. 
53. Botta, M.; Occhionero, F.; Saladino, R.; Crestini, C.; Nicoletti, R. Tetrahedron Lett. 1997, $38,8249$.

54. Saladino, R.; Ciambecchini, U.; Maga, G., Mastromarino, Conti, C.; Botta, M. Bioorg. Med. Chem. 2002, 10, 2143.

55. Botta, M.; Occhionero, F.; Nicoletti, R.; Mastromarino, P.; Conti, C.; Magrini, M.; Saladino, R. Bioorg. Med. Chem. 1999, 7, 1925.

56. J. Med. Chem., submitted.

57. Radi, M.; Petricci, E.; Maga, G.; Corelli, F.; Botta, M. J. Comb. Chem. 2005, 7, 117.

58. Botta, M.; Corelli, F.; Petricci, E.; Radi, M.; Maga, G. Italian Pat. App. RM-2005-A000512. 